\title{
Malignant transformation of neurofibromas at multiple sites in a case of neurofibromatosis
}

\author{
M.D. Leslie and K.Y.P. Cheung ${ }^{1}$ \\ Departments of ' Surgery and Radiotherapy, The Royal Free Hospital, Hampstead, London, NW3, UK.
}

\begin{abstract}
Summary: A patient with classical neurofibromatosis is reported in whom malignant transformation of neurofibromas at multiple sites occurred, leading to a fatal outcome. One of these malignant tumours developed within the thyroid gland.
\end{abstract}

\section{Introduction}

Neurofibromatosis (von Recklinghausen disease) is an autosomal dominant disorder that occurs about once in three thousand live births. ${ }^{1}$ The reported incidence of malignant transformation of neurofibromas in this condition ranges between $2.4 \%{ }^{1}$ and $16.5 \% .^{2}$ We report a patient in which this malignant transformation was observed to occur at multiple sites over a short period of time.

\section{Case report}

The patient, a Caucasian woman, first presented to this hospital in 1975 at the age of 21 years with a painless mass in the left side of the neck which had developed over a period of one year. At the age of 17 , benign neurofibromata had been excised from the right upper arm and left breast at another hospital. There was no family history of neurofibromatosis. Café au lait spots were numerous over the chest and abdomen along with axillary freckling. The neck mass was excised and was found to consist of benign nuerofibromata.

During the next 9 months numerous cutaneous neurofibromata became evident at multiple sites. In October 1983, a painful neurofibroma was excised from the right buttock and histology confirmed its benign nature. In April 1984, further pain in the right buttock was reported, but no abnormality was found on clinical examination. The pain persisted and an enlarging mass in the right buttock became evident over a period of 2 months (Figure 1). Exploration of the buttock revealed a large tumour mass infiltrating the buttock muscles and extending into the pelvis. The bulk of extra pelvic tumour was excised and histology

Correspondence: M.D. Leslie B.Sc., M.R.C.P.

Accepted: 4 September 1986

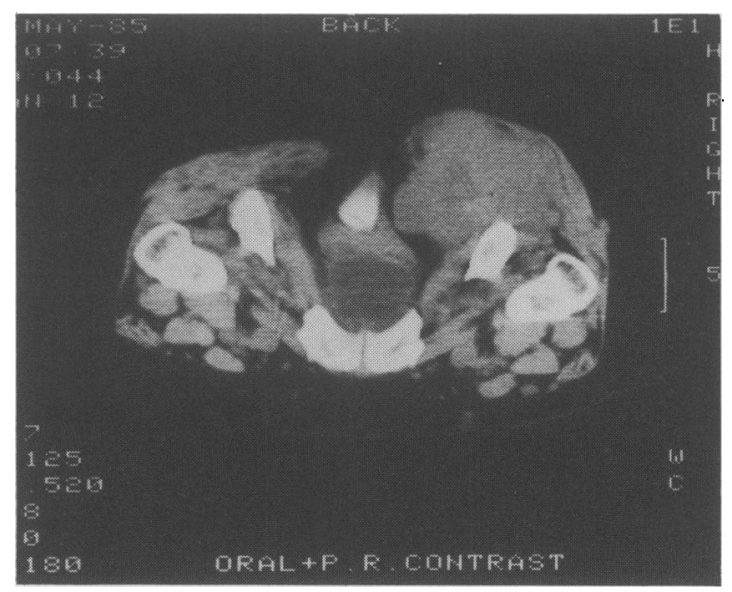

Figure 1 CT scan showing the buttock mass extending into the pelvis and displacing the uterus.

showed malignant schwannoma. Laparotomy was subsequently carried out with the aim of excising the intrapelvic tumour. This was found to involve the muscles of the pelvic floor. Resection would have required mutilating surgery and was not attempted. The residual tumour mass was irradiated to a dose of 60 Gray in 30 fractions with shrinkage of the residual buttock mass.

After a period of 6 months, a rapidly enlarging neurofibroma in the left upper arm was excised and found to have undergone malignant transformation. Within a month, malignant schwannomas were excised from the left side of the neck, left chest wall and from the site of the scar on the right buttock. The patient's condition deteriorated rapidly and neurofibromas at multiple sites, including sites of

(C) The Fellowship of Postgraduate Medicine, 1987 


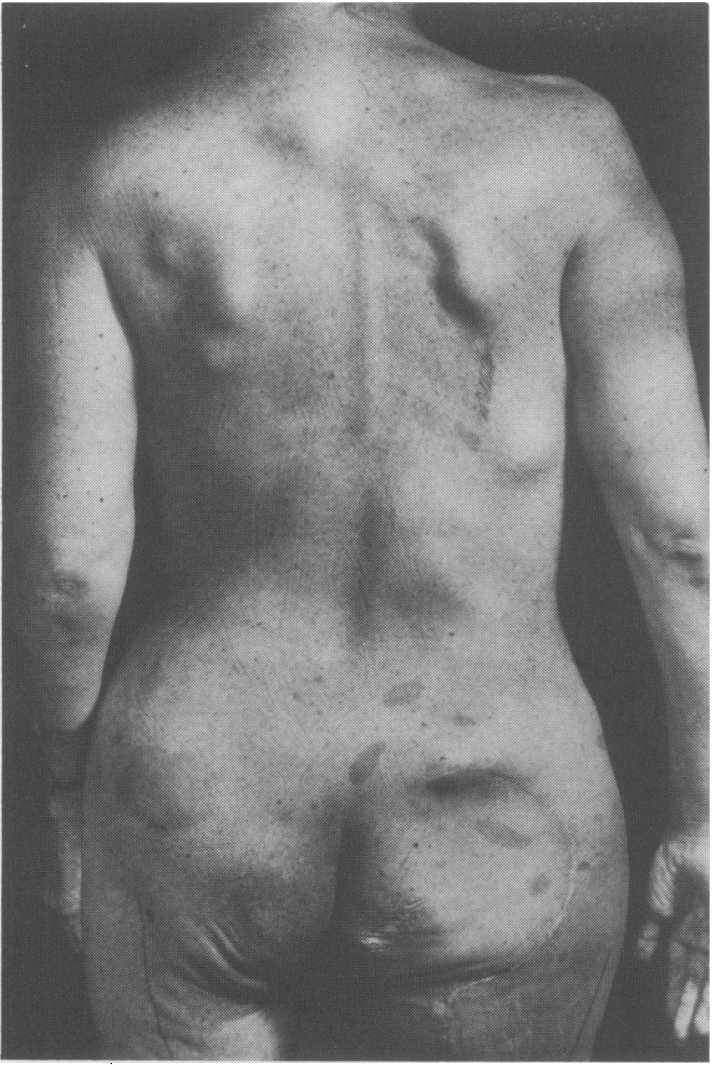

Figure 2 View from the back showing some of the many lesions.

previous excision, enlarged rapidly (Figure 2). Further surgery was not attempted.

Particularly distressing were enlarging tumours in the neck - one arising from the thyroid gland. An ultrasound scan of the neck confirmed a large mass within the right lobe of the thyroid gland and on isotope scanning, the mass was found to be 'cold'. The neck lesions showed regression in response to palliative radiotherapy to a dose of $\mathbf{4 0} \mathrm{Gy}$ given in $\mathbf{2 0}$ fractions.

The patient's general condition continued to deteriorate and she died of her disease at the age of 33 years. Permission for an autopsy was denied but with the family's consent a needle biopsy of the thyroid

\section{References}

1. Crowe, F.W., Schull, W.J. \& Neel, J.V. In A Clinical, Pathological and Genetic Study of Multiple mass was taken. Histology showed it to be malignant $\frac{3}{2}$ schwannoma.

\section{Discussion}

In a case of multiple neurofibromatosis malignant $\frac{\overline{0}}{\overline{0}}$ transformation should be suspected if there is progres- $\frac{\nabla}{\sigma}$ sive enlargement and pain related to a neurofibroma. $\varrho$ Those in whom malignant transformation occurs have of a poor prognosis with a few long-term survivors. ${ }^{3} \overrightarrow{0}$ Radical ablative surgery appears to offer the only hope of cure and results would probably be improved if $\vec{\omega}$ diagnosis could be made earlier. CT scanning is the most useful investigation in evaluating suspicious deep seated lesions ${ }^{4}$ and there have been reports of the value of gallium scanning in detecting malignant transfor- $\omega$ mation. ${ }^{5}$ The factors responsible for progression to $\omega$ malignancy remain unknown. Predisposition to $\%$ malignant transformation has been reported following $\vec{\omega}$ surgical intervention ${ }^{6}$ but this view has not been borne out in later studies. ${ }^{2,3}$ Some reports have suggested that malignant transformation is more likely to occur in $\vec{T}$ internal tissues than in superficial cutaneous lesions. ${ }^{7} \mathbb{D}$

Radiotherapy has been employed in treatment but the tumours are generally considered to be relatively insensitive and high doses need to be employed. ${ }^{8}$ In oயf patient, useful tumour regression was observed wi high doses of photon irradiation. There have be reports on the benefits of using fast neutron therapy treating locally advanced sarcomas. ${ }^{9}$ At one stage chemotherapy was considered but rejected on the grounds of toxicity and the patient's reluctance to embark on such a course of therapy. Response rates of $\mathbb{Q}$ $29 \%$ have been reported using regimes containing doxorubicin. ${ }^{10}$

In this case malignant schwannomas developed at multiple sites (five of which were histologically proven) over a short period of time. We feel the development of multiple primary tumours is the most 3 . likely explanation, but clearly we could have been $\dot{\sigma}$ seeing the manifestations of metastatic disease, particularly in regard to the lesion within the thyroid 8 gland. Such a conclusion has been suggested in a previous case report with some similarities to ours. ${ }^{\text {" }}$ 의

\section{Acknowledgement}

We would like to thank Dr E. Boesen, Mr A. Lewis and Dr F. N Senanayake for their permission and help in reporting on this $N$ patient who was under their joint care.

Neurofibromatosis. Charles C. Thomas, Springfield, Illinois, 1956. 
2. Preston, F.W., Walsh, W.S. \& Clarke, T.H. Cutaneous neurofibromatosis (von Recklinghausen disease). Clinical manifestations and incidence of sarcoma in sixty one male patients. Arch Surg 1952, 64: 813-827.

3. D'Agostino, A.N., Soule, E.H. \& Miller, R.H. Sarcomas of the peripheral nerves and somatic soft tissues associated with multiple neurofibromatosis (von Recklinghausen disease). Cancer 1963, 16: 1015-1027.

4. Coleman, B.G., Arger, P.H., Dalinka, M.K., Obringer, A.C., Raney, B.R. \& Meadows, A.T. CT of sarcomatous degeneration in neurofibromatosis. Am J Radiol 1983, 140: $383-387$.

5. Hammond, J.A. \& Driedger, A.A. Detection of malignant change in neurofibromatosis (von Recklinghausen disease) by Gallium-67 scanning. Can Med Assoc J 1978, 119: $352-353$.

6. Hosoi, K. Multiple neurofibromatosis (von Recklinghausen disease) with special reference to malignant trans- formation. Arch Surg 1931, 22: 265-281.

7. Hunt, K., Jager, R.M., Garreston, H.D. \& Polk, H.C. Neurofibrosarcoma complicating von Recklinghausen disease. J. Ky Med Assoc 1976, 74: 346-349.

8. Carabell, S.C. \& Goodman, R.L. Radiation therapy for soft tissue sarcoma. Semin Oncol 1981, 8: 201-206.

9. Salinas, R., Hussey, D.H., Fletcher, G.H. et al Experience with fast neutron therapy for locally advanced sarcomas. Int J Radiat Oncol Biol Phys 1980, 6: 267272.

10. Rosenberg, S.A., Suit, H.D. \& Baker, L.H. In De Vita, V.T., Hellman, S. and Rosenberg, S.A. (eds) Cancer, Principles and Practice of Oncology, 2nd edition. J.B. Lipincott, Philadelphia, 1985, p. 1282.

11. Corkill, A.G.L. \& Ross, C.F. A case of neurofibromatosis complicated by medulloblastoma, neurogenic sarcoma, and radiation induced carcinoma of thyroid. J Neurol Neurosurg Psychiat 1969, 32:43- 47. 